\title{
The role of MeCP2 in learning and memory
}

\author{
Holly A. Robinson and Lucas Pozzo-Miller \\ Department of Neurobiology, The University of Alabama at Birmingham, Birmingham, Alabama 35294, USA
}

\begin{abstract}
Gene transcription is a crucial step in the sequence of molecular, synaptic, cellular, and systems mechanisms underlying learning and memory. Here, we review the experimental evidence demonstrating that alterations in the levels and functionality of the methylated DNA-binding transcriptional regulator MeCP2 are implicated in the learning and memory deficits present in mouse models of Rett syndrome and MECP2 duplication syndrome. The significant impact that MeCP2 has on gene transcription through a variety of mechanisms, combined with well-defined models of learning and memory, make $\mathrm{MeCP} 2$ an excellent candidate to exemplify the role of gene transcription in learning and memory. Together, these studies have strengthened the concept that precise control of activity-dependent gene transcription is a fundamental mechanism that ensures long-term adaptive behaviors necessary for the survival of individuals interacting with their congeners in an ever-changing environment.
\end{abstract}

The roles of gene transcription and mRNA translation in learning and memory throughout the animal kingdom have been extensively and very well defined over the past five decades. Studies inhibiting gene transcription demonstrate its necessity for learning and memory in both invertebrates and vertebrates (Brink et al. 1966; Thut and Lindell 1974; Wetzel et al. 1976; Pedreira et al. 1996). In rats, during both memory consolidation (Taubenfeld et al. 2001; Garcia-Osta et al. 2006; Bekinschtein et al. 2007; Chen et al. 2011) and memory reconsolidation (Da Silva et al. 2008), at least one phase of gene transcription is required, and in some cases, like avoidance memory formation, multiple phases of transcription are required (Igaz et al. 2002). Gene transcription also plays a fundamental role in long-term plasticity of excitatory synaptic transmission (i.e., long-term potentiation and long-term depression) in invertebrates and vertebrates via the transcriptional regulation of genes encoding proteins responsible for the formation of new synapses and the structural remodeling of existing ones, which results in lasting changes in synaptic strength (Davis and Squire 1984; Tully et al. 1994).

Methyl CpG binding protein $2(\mathrm{MeCP} 2)$ is an X-linked global transcriptional regulator that binds methylated sites in DNA, and whose dysfunction is implicated in two severe neurological disorders: Rett syndrome and MECP2 duplication syndrome. Rett syndrome is caused by loss-of-function mutations in MECP2 (Amir et al. 1999), while MECP2 duplication syndrome is caused by a gain-of-function due to the overexpression of MECP2 (Van Esch et al. 2005). Because several mouse models of both syndromes show altered learning and memory, MeCP2 is an excellent candidate for the examination of the role of epigenetic regulation of gene transcription in learning and memory. Here, we review experimental observations on the role of MeCP2 in the regulation of gene transcription and learning and memory in rodent models.

\section{Molecular mechanisms of MeCP2 function}

In addition to its strict definition by Waddington (i.e., "the various developmental pathways a cell might take toward differentiation"), the term epigenetics is also used to describe the tagging of DNA and

\section{Corresponding author: lucaspm@uab.edu}

Article is online at http://www.learnmem.org/cgi/doi/10.1101//m.048876. 118.
DNA-associated histones, which leads to transient or enduring regulation of gene transcription without changes in the gene coding sequence itself. The most common occurrence of epigenetic modification is during the differentiation of specific cell types by the regulation of the chromatin structure (Rakyan et al. 2001). Epigenetic modifications include methylation of DNA, as well as acetylation, phosphorylation, methylation, ubiquitylation, and SUMOylation of histones (Hebbes et al. 1988; Zhang 2003; Miller et al. 2010; Sánchez-Álvarez et al. 2010; Zovkic et al. 2013; Meas and Mao 2015). Histone acetylation and phosphorylation both typically function as transcriptional activators (Hebbes et al. 1988; Mujtaba et al. 2007). Histone methylation and SUMOylation act as transcriptional repressors (Whetstine 2009; Sánchez-Álvarez et al. 2010). Both DNA methylation (Chahrour et al. 2008) and ubiquitylation (Zhang 2003; Meas and Mao 2015) can result in either transcriptional activation or repression. $\mathrm{MeCP} 2$ is the founding member of the methyl-DNA binding proteins (MBD), and was discovered several years before its role in Rett syndrome and MECP2 duplication syndrome was recognized (Lewis et al. 1992; Amir and Zoghbi 2000).

DNA methylation adds a methyl group at the $5^{\prime}$ position on the cytosine pyrimidine rings (Holliday and Pugh 1975), creating a carbon-carbon bond that is very stable. MeCP2 binding to methylated CpG sites causes the interaction with the histone deacetylase complex (Maunakea et al. 2013). It is important to note that $\mathrm{MeCP} 2$ is preferentially localized to the pericentromeric heterochromatin, which has the highest concentration of 5-methylcytosine (Nan et al. 1996). This carbon-carbon bond stability helps to prevent demethylation (Wolffe et al. 1999); however, in rare cases, spontaneous demethylation can occur. In the event of spontaneous demethylation, the methylated compound is resynthesized (Ma et al. 2009). When MeCP2 binds to methylated DNA it interacts with either the mSin3A/HDAC corepressor complex (Nan et al. 1998) or CREB (Chahrour et al. 2008), which results in transcriptional repression or transcriptional activation, respectively (discussed in further detail below) (Fig. 1). The NCoR/SMRT

(C) 2019 Robinson and Pozzo-Miller This article is distributed exclusively by Cold Spring Harbor Laboratory Press for the first 12 months after the fullissue publication date (see http://learnmem.cshlp.org/site/misc/terms.xhtml). After 12 months, it is available under a Creative Commons License (Attribution-NonCommercial 4.0 International), as described at http:// creativecommons.org/licenses/by-nc/4.0/. 


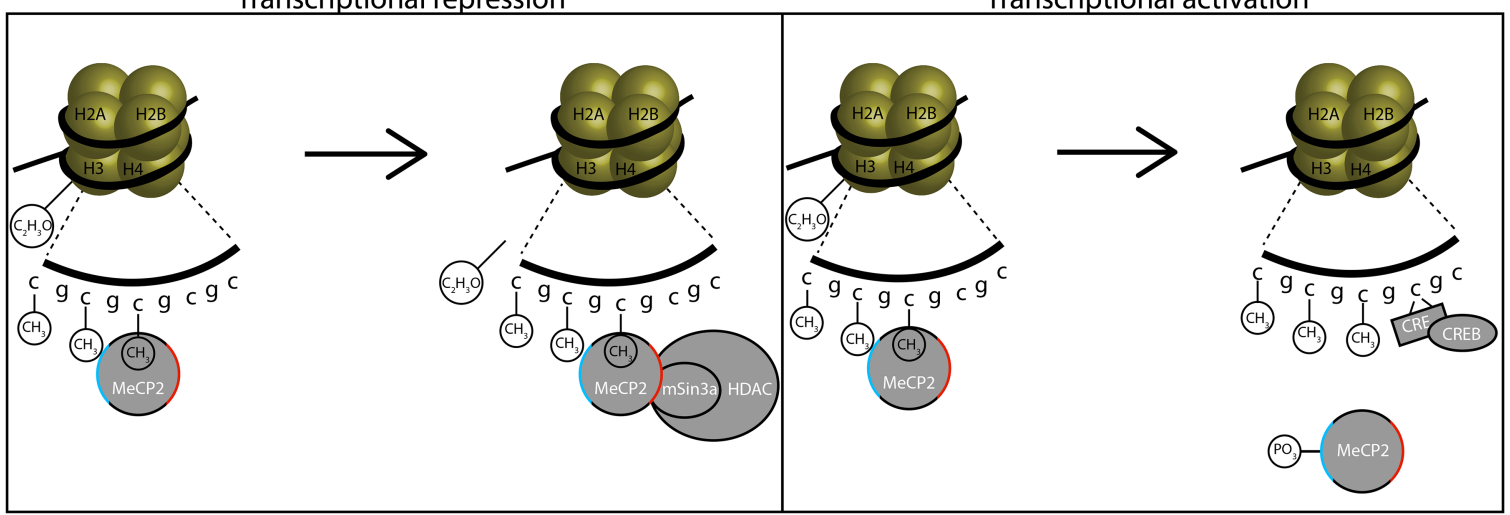

Figure 1. The role of $\mathrm{MeCP} 2$ in learning and memory through transcriptional repression and activation. Altered deacetylation results in altered transcriptional repression, resulting in impaired spatial memory, fear learning, and social memory. Preventing MeCP2 phosphorylation results in no release from $B d n f$, resulting in improved spatial memory and fear learning.

complexes are known corepressors needed for transcriptional repression that have also been found to directly bind to MeCP2. Additionally, the cSki/Sno complex is found to directly bind to MeCP2. Successful binding of cSki/Sno to MeCP2 is necessary for transcriptional repression (Kokura et al. 2001). These interactions alter the reading of the DNA by RNA polymerase II. Altering the conformation of the DNA being read by RNA polymerase II results in either the silencing of mRNA transcription or the transcription of the mRNA transcript (Kriaucionis and Bird 2003).

$\mathrm{MeCP} 2$ is highly localized to pericentromeric heterochromatin due to its binding to methylated cytosine (mC) in CG (mCG) and, to a less extent, $\mathrm{mCH}(\mathrm{H}: \mathrm{A}, \mathrm{C}$, or $\mathrm{T})$ pairs. While MeCP2 has the propensity to interact with any cytosine rich region, interactions with methylated CpG islands are the most thoroughly studied, and will be the focus of this review (Lewis et al. 1992; Hendrich and Tweedie 2003). MeCP2 interaction with methylated sites throughout the gene body results in both transcriptional activation and repression (Chahrour et al. 2008). When an organized chromatin structure is not present, MeCP2 selectively represses transcription of methylated templates (Nan et al. 1997; Kaludov and Wolffe 2000). One hypothesis for the pathogenesis of Rett syndrome is that loss-of-function mutations in the MECP2 gene are detrimental because they result in the lack of MeCP2-mediated silencing of transcriptional noise (Bird and Tweedie 1995). It has also been suggested that $\mathrm{MeCP} 2$ controls the expression of long genes (more than $100 \mathrm{~kb}$ ) in a length-dependent manner (Gabel et al. 2015), although this view is controversial (Raman et al. 2018). Regardless of the specific molecular mechanism(s) of MeCP2 regulation of gene expression (Guy et al. 2011), there is ample consensus that MeCP2 is a critical component of the gene structure required for proper transcription. Considering its stoichiometry to DNA (Nan et al. 1997), its abundance significantly affects gene transcription (Fig. 1).

\section{Mechanisms of MeCP2 mediated transcriptional repression} In vitro experiments have shown that transcriptional repression occurs via the formation of aggregates of MeCP2 on the DNA template, preventing transcription complexes from forming (Kaludov and Wolffe 2000). Similar aggregation is observed in the nuclei at foci containing methylated DNA (Nan et al. 1996). After binding methylated DNA, MeCP2 impacts transcription by restricting access to RNA polymerase II, as well as by splicing mRNA and association with mRNA already spliced by MeCP2 (Long et al. 2011).

$\mathrm{MeCP} 2$ also represses transcription by the interaction between chromatin, DNA methylation, and histone deacetylation.
In $\mathrm{MeCP} 2$, the chromatin infrastructure recognizes methylated CpG dinucleotides in the nucleosome (Chandler et al. 1999). When bound to DNA, MeCP2 can displace histone H1 from chromatin, which allows MeCP2 access to its binding sites (Nan et al. 1997). In short, MeCP2 is involved in the modification of the chromatin structure directly or through other repressive enzymes (Robertson and Wolffe 2000). Alteration of the chromatin structure interacts with islands of $\mathrm{CpG}$, allowing for transcriptional repression (Nan et al. 1997). One region of MeCP2 contains a transcriptional repression domain that allows binding to the corepressor complex mSin3A/HDAC through interaction with mSin3A. This indicates that both histone deacetylation and DNA methylation are necessary for MeCP2 to repress transcription (Nan et al. 1998). Additionally, it is likely that MeCP2 interactions with NCoR/SMRT and cSki/Sno complexes, in concert with the mSin3A/HDAC complex, are necessary for successful MeCP2-mediated transcriptional repression (Kokura et al. 2001).

\section{Mechanisms of MeCP2 mediated transcriptional activation}

MeCP2 can also function as a transcriptional activator: MeCP2 copurifies with multiple proteins including the well-known transcriptional activator, CREB1. In addition, MeCP2 binds to the promoter region of Creb1. While deletion of Mecp2 causes more transcriptional repression than activation, duplication of Mecp2 results in more activation than repression (Chahrour et al. 2008). Binding of MeCP2 has been observed at the promoter region of Sst, Oprk1, Gamt, Gprin1, Mef2c, and A2bp1, all genes that show a bimodal expression between mouse models of Mecp2 deletion and MECP2 overexpression. Binding of MeCP2 was not detected at the promoter region of genes which are down-regulated in both mouse models. The genes that show MeCP2 binding also show increased binding in Mecp 2 overexpressing mice as compared to wild-type mice (Chahrour et al. 2008). In addition, Mecp2 binding to RNASEH2A is responsible for up-regulation of its transcription, while Mecp2 deletion results in lower RNASEH2A transcription (Yasui et al. 2007). Together, these findings suggest that MeCP2 does not prevent the binding of repressors, but rather recruits transcriptional activators (Yasui et al. 2007; Chahrour et al. 2008).

\section{Phosphorylation of MeCP2}

Posttranslational modifications like phosphorylation are wellcharacterized mechanisms that alter protein function. MeCP2 is 
phosphorylated at serine 80 (S80) and serine 421 (S421). When S80 is dephosphorylated, MeCP2 binds less strongly to chromatin regions. While neuronal activity induces phosphorylation at S421, it reduces phosphorylation at $\mathrm{S} 80$. It has been suggested that phosphorylation of MeCP2 at these sites promotes the transition between the resting state and the depolarized state of the neuron (Tao et al. 2009). S80 phosphorylation allows for binding of MeCP2 to chromatin during resting states, while S421 phosphorylation allows for disassociation from the chromatin during neuronal depolarizations. Alterations of phosphorylation of S80 can cause transcriptional changes to a small number of genes but does not impair global gene transcription. However, the transition between resting and depolarized states that is assisted by phosphorylation of MeCP2 causes shifts in gene transcription (Tao et al. 2009).

\section{Experimental animal models to characterize $\mathrm{MeCP} 2$ function}

Rett syndrome is modeled in mice carrying a constitutive deletion of one or two of the coding exons in the Mecp2 gene, or the insertion of a premature STOP codon at specific sites to generate a truncated MeCP2 protein, as well as by cell type-specific or brain region-specific deletions of Mecp2 exons using the Cre-loxP system (for review, see Li and Pozzo-Miller 2012).

One of the two constitutive Mecp2 knockout (KO) mouse models was generated using the Cre recombinase-loxP system, inserting loxP sites flanking exons 3 and 4 of the Mecp2 gene, which results in their deletion in Cre-expressing cells ("Bird" line) (Guy et al. 2001). The other constitutive Mecp2 KO mouse model carries a Cre-loxP deletion of exon 3 ("Jaenisch" line) (Chen et al. 2001). While these Mecp2 exon deletions result in truncated peptides, these are nonfunctional. Male mice of both these constitutive Mecp2 KO lines develop a combination of neurological phenotypes at around 2 mo of age, which are reminiscent of the symptoms presented by Rett syndrome individuals. Due to the mosaic pattern of mutant and nonmutant cells resulting from random $\mathrm{X}$-chromosome inactivation, female heterozygous (Het) mice of both lines show a delayed onset of the same Rett-like neurological phenotypes.

Mice carrying a premature STOP codon at position 308 were generated to model the consequences of MECP2 mutations that result in truncated $\mathrm{MeCP} 2$ protein in some Rett syndrome individuals (Shahbazian et al. 2002). Similar to the mild clinical presentation in these Rett syndrome individuals, male Mecp $2^{308}$ mice have milder phenotypes and longer lifespan than constitutive $\mathrm{KO}$ mice (Shahbazian et al. 2002).

Conditional Mecp2 KO mice were later developed using the Cre-loxP system, with Cre expression driven by promoters that are expressed in specific cell types or different brain regions, including Camkii-expressing excitatory forebrain neurons (Chen et al. 2001), Sim1-expressing hypothalamic neurons (Fyffe et al. 2008), Th-expressing dopaminergic/noradrenergic neurons (Samaco et al. 2009), Pet1-expressing serotonergic neurons (Samaco et al. 2009), Viaat-expressing inhibitory interneurons (Chao et al. 2010), Dlx5/6-expressing forebrain inhibitory interneurons (Chao et al. 2010), and Gfap-expressing astrocytes (Lioy et al. 2011).

The combination of Cre-loxP deletions of Mecp2 with the inducible expression of Cre recombinase using the estrogen receptor system allowed the demonstration that some Rett-like phenotypes are reversible in fully symptomatic adult mice (Guy et al. 2007). A similar inducible Cre-loxP approach also demonstrated that MeCP2 is continuously required for proper function because its deletion in asymptomatic adult mice result in the abrupt appearance of Rett-like phenotypes (McGraw et al. 2011).
Because almost a third of Rett syndrome individuals carry nonsense mutations (Neul et al. 2008), mouse models with similar mutations were generated for preclinical studies of read-through compounds that skip premature STOP codons and produce fulllength mRNA transcripts and proteins, including R168X (Brendel et al. 2011) and R255X (Pitcher et al. 2015). It is interesting to note that MeCP2 binds to the NCoR/SMRT complex at amino acids 269-309, a series which overlaps with the cluster of Rett syndrome missense mutations. Loss of NCoR/SMRT-MeCP2 interaction has been implicated in several Rett syndrome phenotypes (Lyst et al. 2013), making this model particularly useful for clinical research.

In an effort to increase translation from the bench to the clinic, new experimental models of Rett syndrome have been developed using rats and nonhuman primates. A rat model of Rett syndrome was created using the zinc-finger nuclease strategy $\left(\mathrm{Mecp} 2^{\mathrm{ZFN}}\right)$, which resulted in the deletion of 71 base pairs in exon 4 that caused posttranscriptional loss of Mecp2 (Veeraragavan et al. 2016). CRISPR/Cas9 and TALEN-mediated mutagenesis were used to edit the Mecp2 gene in rhesus and cynomolgus monkeys to generate models of Rett syndrome (Liu et al. 2014; Niu et al. 2014).

MECP2 duplication syndrome was discovered in humans after a distinct neurological phenotype was described in MECP2 overexpressing mice (Collins et al. 2004). These mice were generated through the microinjection of linearized PAC671D9 into fertilized oocytes. This is a $99 \mathrm{~kb}$ human clone which contains all exons of the human MECP2 gene. These observations led to the discovery of $M E C P 2$ duplication syndrome as a new clinical entity in humans (Ramocki et al. 2010). More recently, another mouse model of MECP2 duplication syndrome was generated by targeting Mecp2 expression in the locus of the neuron-specific gene Tau. This model exhibits a wide array of phenotypes seen in MECP2 duplication syndrome ( $\mathrm{Na}$ et al. 2012).

In addition, the consequences of posttranslational modifications of MeCP2 have been studied in transgenic knock-in mice. For example, Mecp $2^{\mathrm{S} 421 \mathrm{~A} ; \mathrm{S} 424 \mathrm{~A}}$ knock-in mice carry phosphorylation sites that result in Mecp2 overexpression (Li et al. 2011). However, it is important to note that these mutations have not been discovered yet in humans.

Deficits in learning and memory are consistently found in all the mutant mouse lines that carry loss-of-function mutations, truncations, and deletions of the Mecp2 gene as well as in all models of MECP2 duplication syndrome. These impairments vary in a way that allows for identifying specific molecular mechanisms and cell types, as well as microcircuits and long-range projections responsible for specific behaviors (Adachi et al. 2009; Chao et al. 2010; Li et al. 2011; Durand et al. 2012; Ito-Ishida et al. 2015; Krishnan et al. 2017; Phillips et al. 2019). However, it is important to note that the behavioral phenotypes expressed in these mouse models depend critically on the genetic background of the mouse, the sex of the mouse, and the assay used for behavioral testing which results in some degree of variance between experiments; this will be exemplified in the Consequences of MeCP2 dysfunction in learning and memory section. The next sections will describe these processes and mechanisms in more detail.

\section{Consequences of MeCP2 dysfunction in learning and memory}

\section{Spatial memory}

Spatial memory is defined as the recognition, encoding, storage, and retrieval of information involving the arrangement of objects within an area or pathways through the area (Kessels et al. 2001). Spatial memory is tested in rodents using mazes such as Y-mazes, 
T-mazes, circular mazes, radial mazes, arena mazes, and the Morris water maze. While each of these methods have their own advantages and disadvantages, the fundamental purpose of each maze is to test how well animals can remember the location of safety or rewards, such as food or water, through visual-spatial signals (Paul et al. 2009). While more recent functional imaging and neuronal inactivation experiments have shown that the prefrontal and anterior cingulate cortex, the parietal cortex, and the retrosplenial cortex are involved in the storage and retrieval of spatial memory (Maviel et al. 2004), the hippocampus has been shown to be critical for the formation of spatial memory for over four decades (Olton et al. 1978). This has allowed spatial memory tasks to be a prime marker for testing hippocampal-dependent memory.

Female Mecp2 Het mice show deficits in spatial memory using the Morris water maze (Hao et al. 2015), the "novel object location" task (Li et al. 2017), as well as using a rectangular tract maze with spatial cues (Kee et al. 2018). Mice with conditional deletion of Mecp2 from GABAergic inhibitory interneurons show impairments in spatial memory tasks using the Morris water maze (Chao et al. 2010). There have been attempts to test constitutive male Mecp2 KO mice using the Morris water maze, but because they have hindered motor performance and have difficulties swimming, cognitive performance is difficult to assess using this test (Stearns et al. 2007). The first report of male $M e c p 2^{308}$ mice described typical performance in the Morris water maze (Shahbazian et al. 2002), which was attributed to residual function of the truncated MeCP2 protein being expressed. Later it was found that male Mecp $2^{308}$ mice on a pure 129 background did show impairments in the Morris water maze (Moretti et al. 2006). This contrasting phenotype can be contributed to the difference in genetic background and will be discussed again in the sections Contextual and cued fear conditioning and Social memory.

Additional evidence of the role of MeCP2 in spatial memory was obtained from phospho-mutant knock-in mice (Li et al. 2011). As discussed above, neuronal activity induces phosphorylation of MeCP2 at S421, which causes its release from chromatin (Tao et al. 2009). In addition, MeCP2 phosphorylation at S421 precedes its release from the promoter region of the gene encoding brain-derived neurotrophic factor $(B d n f)$, which results in its transcription (Chen et al. 2003; Zhou et al. 2006). Mecp2 $2^{\text {S421A;S424A }}$ knock-in mice were generated to study the impact of activitydependent MeCP2 phosphorylation in vivo. These MeCP2 phospho-mutant mice do not show overt neurological phenotypes, and have a typical healthy lifespan, which makes them amenable for multiple behavioral tests that other Mecp2 mutant mice do not withstand. Intriguingly, male Mecp $2^{\mathrm{S} 421 \mathrm{~A} ; \mathrm{S} 424 \mathrm{~A}}$ knock-in mice spent significantly more time in the target region during the hidden platform session of the Morris water maze as compared to wild-type littermates, indicating improved spatial memory ( $\mathrm{Li}$ et al. 2011). These mice also show larger long-term potentiation, higher numbers of excitatory synapses, and $B d n f$ mRNA levels in the hippocampus. These results are in agreement with earlier work demonstrating the role of BDNF in hippocampal long-term potentiation and hippocampal-dependent spatial memory (Figurov et al. 1996; Ma et al. 1998).

\section{Contextual and cued fear conditioning}

Contextual fear learning is a learning task that requires the hippocampus and the amygdala. Contextual fear learning tests the ability of a subject to associate an unpleasant stimulus with a specific environment (Phillips and LeDoux 1992). Learning is measured by freezing behaviors in the environment where the mouse received the footshock as compared to other environments. Cued-fear learning is amygdala-dependent learning activity in which mice receive a footshock after a given cue (Blanchard and
Blanchard 1972; Phillips and LeDoux 1992). Learning is measured by freezing behavior given the cue associated with the footshock as compared to other cues. Contextual fear conditioning is often used to evaluate hippocampal-dependent memory, while cued fear conditioning is used as an evaluation of amygdala-dependent memory.

Constitutive male Mecp2 KO mice show impaired cued fear memory, while female Mecp2 Het mice do not (Stearns et al. 2007). However, female Mecp2 Het mice do show deficits in contextual fear memory (Samaco et al. 2013), while male Mecp2 KO mice do not (Stearns et al. 2007). These results suggest that there is a large sex-dependent component in hippocampal function, where the mosaic pattern of mutant Mecp2 expression in different cells in female Mecp2 Het mice contributes to hippocampal-dependent memory. It was later described that female Mecp2 Het mice show intact contextual fear memory over short periods of time, but impaired contextual fear memory over longer time spans (Kee et al. 2018).

Similar to deficits in hippocampal-dependent spatial memory, $M e c p 2^{308}$ mice in a mixed C57 and 129 genetic background show normal contextual fear conditioning (Shahbazian et al. 2002), while the same allele in a pure 129 genetic background results in impaired contextual fear memory (Moretti et al. 2006), once more demonstrating the importance of taking into account the genetic background of a model used for behavioral testing. On the other hand, MECP2 overexpression results in increased freezing in both contextual and cued fear conditioning (Collins et al. 2004). Conditional Mecp2 deletion in Sim1-expressing neurons in the hypothalamus does not affect fear learning (Fyffe et al. 2008), confirming that the behavioral consequences of Mecp2 deletion reflect its necessity for proper neuronal function in the brain regions responsible for those behaviors.

To determine the role of activity-dependent phosphorylation of MeCP2 in different types of memory tasks, the phospho-mutant Mecp $2^{\text {S421A;S424A }}$ knock-in mice discussed above were also tested in fear learning. These mice exhibit increased freezing compared to wild-type littermates in contextual fear learning, but not in cued fear learning (Li et al. 2011). Much like with spatial memory, the increased freezing observed in Mecp $2^{\mathrm{S421A} ; \mathrm{S} 424 \mathrm{~A}}$ knock-in mice during contextual fear learning is likely due to increased hippocampal activity resulting from the absence of activity-dependent S421 phosphorylation (Li et al. 2011).

Targeted Mecp2 deletion in the basolateral amygdala of male mice causes increased freezing during cued fear learning, which is thought to result from increased $\mathrm{H} 3$ acetylation, due to loss of transcriptional repression by MeCP2 (Adachi et al. 2009). This type of experiment exemplifies the specificity yielded by targeted deletions of $M e c p 2$ in selected brain regions, which provide complementary information to that obtained from constitutive Mecp2 KO mice throughout the brain.

\section{Social memory}

Studies focusing on social behaviors in mouse models of autism spectrum disorders are becoming increasingly useful because deficits of social interactions are often early markers of these neurodevelopmental disorders. In mouse studies, sociability is defined as the preference of the test mouse for another mouse over an inanimate object or an empty side chamber. Such preference is most commonly tested using a 3-chamber assay in which the test mouse is placed in a center chamber connected to a side chamber containing a target mouse restrained in an inverted pencil cup on one side, and to another side chamber containing an empty inverted pencil cup (Moy et al. 2004) or an inanimate object (Silverman et al. 2010). In the slightly different "partition test," a cage is divided in half with a perforated transparent wall that allows the test 
mouse to see, hear, and smell the target mouse but cannot physically interact with it (Silverman et al. 2010). In these tests, social memory is defined as the time-delayed recognition of a familiar mouse, meaning that a mouse can distinguish a familiar mouse from a novel mouse (Silverman et al. 2010). Therefore, social memory can be measured as the preference for interaction with a novel mouse over a familiar mouse using a 3-chamber assay with one chamber containing a novel mouse and a second chamber containing a familiar mouse (Moy et al. 2004). Similarly, social memory can be assayed with a partition test with a familiar and novel mouse with separate partitions, as well as in Y-mazes in which a novel and familiar mouse are contained in cages in the two arms of the maze. In addition, the novel and familiar mice can be introduced to the test simultaneously or sequentially with a time delay (Silverman et al. 2010). Recent advances in computer vision and machine learning now allow quantitative and unbiased analyses of individual mouse behaviors as well as social interactions between test and target mice within an open field, which allow assessing sociability and social memory with unrestricted familiar and novel target mice (Kabra et al. 2013; Ohayon et al. 2013; Robie et al. 2017; Phillips et al. 2019).

Several studies have investigated social behaviors in Mecp2 mutant mice, with seemingly contrasting results (for review, see Pearson et al. 2012). Constitutive male Mecp2 KO mice of the "Jaenisch" line show increased sociability and social memory in the 3-chamber assay (Schaevitz et al. 2010), while a recent study using the same mouse line describes normal social preference but impaired social memory in both the 3-chamber test and in unrestricted social interactions with familiar and novel mice (Phillips et al. 2019). It is important to consider variations in how "interaction" is defined, as Pearson et al. considered interaction as time spent in the chamber, while Phillips et al. considered interaction as active investigation of the pencil cup by the test subject; additionally Phillips et al. only used the first 4 min out of the $10 \mathrm{~min}$ unrestricted social interaction as even wild-type mice show a loss of interest in either mouse after $4 \mathrm{~min}$.

Consistent with a slower progression of Rett-like phenotypes, female Mecp2 Het mice show normal sociability in the 3-chamber assay at $12 \mathrm{wk}$ of age, but they develop impaired sociability at 22 wk of age (McGraw et al. 2011). Male Mecp2 ${ }^{308}$ mice expressing a truncated protein (in a pure 129 background) showed reduced sociability in the partition test, without apparent deficits in the recognition of familiar mice (Moretti et al. 2005), in addition to impaired long-term social memory (Moretti et al. 2006). On the other hand, male Mecp $2^{308}$ mice in a pure C57/BL6J background showed typical sociability in the 3-chamber test (Pearson et al. 2012). The differing results between male and female models show the importance of taking into account sex-specific differences in all studies, particularly those involving models with Mecp2 mutations. The opposing results between the same mouse line in different genetic backgrounds once more exemplifies how great of an impact background can have on all types of behavior.

The $\sim 40 \%$ reduction in Mecp2 expression that results from the insertion of loxP sites flanking exons 3 and 4 (without Cre expression) also causes increased sociability in the partition test (Samaco et al. 2008). However, another study using the same Mecp2 hypomorphic mice described increased social memory with normal sociability using a 3-chamber assay (Kerr et al. 2008). When these floxed Mecp 2 mice were crossed with mice expressing Cre under control of the Sim1 promoter (to delete Mecp2 in hypothalamic neurons), both the conditional Sim1 Mecp2 KO mice and the floxed Mecp2 hypomorphs spent more time on the partition facing the novel mice than the wild-type and Sim1-Cre controls (Fyffe et al. 2008), again indicating that a $40 \%$ reduction in Mecp 2 levels affects certain behaviors and not others.
Similarly, conditional deletion of Mecp2 in forebrain GABAergic inhibitory interneurons results in increased sociability in both the 3-chamber assay and the partition test (Chao et al. 2010). In contrast, conditional deletion of $M e c p 2$ in forebrain excitatory neurons of postnatal mice causes reduced sociability using a modified partition test, in addition to impaired social memory in an unrestricted behavioral assay in which mice habituated to a target mouse for $4 \mathrm{~d}$ and the target mouse is replaced with a novel mouse on the fifth day (Gemelli et al. 2006), as well as lower social preference in the 3-chamber test (Chin et al. 2018). This exemplifies the usefulness of conditional KOs in behavioral testing.

Finally, both male Mecp2 KO rats (Wu et al. 2016) and female Mecp2 Het rats (Veeraragavan et al. 2016) show impaired sociability in the 3-chamber assay. Taken together, these studies suggest sexspecific differences in the consequences of Mecp 2 deletion on social behavior. Furthermore, the mosaic pattern of mutant Mecp2 expression in different cells in female Mecp2 Het mice contributes to those differences in social behaviors.

\section{Conclusions}

Through many decades of rigorous and exhaustive research, it has become widely accepted that proper gene transcription is critical for learning and memory (Brink et al. 1966; Thut and Lindell 1974; Wetzel et al. 1976; Pedreira et al. 1996) at multiple timepoints during this complex process (Taubenfeld et al. 2001; Garcia-Osta et al. 2006; Bekinschtein et al. 2007; Chen et al. 2011). Transcriptional regulators such as MeCP2 are critical for ensuring that gene transcription proceeds successfully. MeCP2 has complex functions in brain cells including mediating both transcriptional activation and repression (Fig. 1; Guy et al. 2011). Different manipulations of the $M e c p 2$ gene locus results in different levels of MeCP2 protein expression, in addition to the expression of nonfunctional truncated peptides, with all leading to altered levels of gene transcription, resulting in impairments of learning and memory. Together, these studies provide further evidence to support that precise control of activity-dependent gene transcription is necessary to ensure long-term adaptive behaviors required for the survival of individuals interacting with their conspecifics in a fluid world.

\section{Competing interest statement}

The authors do not have competing financial interests.

\section{Acknowledgments}

The authors thank Dr. Mary Phillips, Dr. Anderson Butler, Dr. Wei $\mathrm{Li}$, and Dr. Alan Percy (all at UAB) for their comments on the manuscript, and Dr. Cristin Gavin and the UAB Undergraduate Neuroscience Program for their guidance and support. This work was funded by the National Institutes of Health (NIH) grant R56-NS103089-01A1 (L.P.-M.).

\section{References}

Adachi M, Autry AE, Covington HE III, Monteggia LM. 2009.

MeCP2-mediated transcription repression in the basolateral amygdala may underlie heightened anxiety in a mouse model of Rett syndrome. $J$ Neurosci 29: 4218-4227. doi:10.1523/JNEUROSCI.4225-08.2009

Amir RE, Zoghbi HY. 2000. Rett syndrome: methyl-CpG-binding protein 2 mutations and phenotype-genotype correlations. Am J Med Genet 97: 147-152. doi:10.1002/1096-8628(200022)97:2<147::AID-AJMG6>3.0 .CO;2-O

Amir RE, Van den Veyver IB, Wan M, Tran CQ, Francke U, Zoghbi HY. 1999. Rett syndrome is caused by mutations in X-linked MECP2, encoding methyl-CpG-binding protein 2. Nat Genet 23: 185-188. doi:10.1038/ 13810 
Bekinschtein P, Cammarota M, Igaz LM, Bevilaqua LR, Izquierdo I, Medina JH. 2007. Persistence of long-term memory storage requires a late protein synthesis- and BDNF-dependent phase in the hippocampus. Neuron 53: 261-277. doi:10.1016/j.neuron.2006.11.025

Bird A, Tweedie S. 1995. Transcriptional noise and the evolution of gene number. Philos Trans R Soc Lond B Biol Sci 349: 249-253. doi:10.1098/ rstb.1995.0109

Blanchard DC, Blanchard RJ. 1972. Innate and conditioned reactions to threat in rats with amygdaloid lesions. J Comp Physiol Psychol 81: 281290. doi:10.1037/h0033521

Brendel C, Belakhov V, Werner H, Wegener E, Gärtner J, Nudelman I, Baasov T, Huppke P. 2011. Readthrough of nonsense mutations in Rett syndrome: evaluation of novel aminoglycosides and generation of a new mouse model. J Mol Med (Berl) 89: 389-398. doi:10.1007/ s00109-010-0704-4

Brink JJ, Davis RE, Agranoff BW. 1966. Effects of puromycin, acetoxycycloheximide and actinomycin $\mathrm{D}$ on protein synthesis in goldfish brain. J Neurochem 13: 889-896. doi:10.1111/j.1471-4159.1966 .tb10284.x

Chahrour M, Jung SY, Shaw C, Zhou X, Wong ST, Qin J, Zoghbi HY. 2008. $\mathrm{MeCP} 2$, a key contributor to neurological disease, activates and represses transcription. Science 320: 1224-1229. doi:10.1126/science.1153252

Chandler SP, Guschin D, Landsberger N, Wolffe AP. 1999. The methyl-CpG binding transcriptional repressor MeCP2 stably associates with nucleosomal DNA. Biochemistry 38: 7008-7018. doi:10.1021/bi990224y

Chao HT, Chen H, Samaco RC, Xue M, Chahrour M, Yoo J, Neul JL, Gong S, Lu HC, Heintz N, et al. 2010. Dysfunction in GABA signalling mediates autism-like stereotypies and Rett syndrome phenotypes. Nature 468: 263-269. doi:10.1038/nature09582

Chen RZ, Akbarian S, Tudor M, Jaenisch R. 2001. Deficiency of methyl-CpG binding protein-2 in CNS neurons results in a Rett-like phenotype in mice. Nat Genet 27: 327-331. doi:10.1038/85906

Chen WG, Chang Q, Lin Y, Meissner A, West AE, Griffith EC, Jaenisch R, Greenberg ME. 2003. Derepression of BDNF transcription involves calcium-dependent phosphorylation of MeCP2. Science 302: 885-889. doi:10.1126/science.1086446

Chen DY, Stern SA, Garcia-Osta A, Saunier-Rebori B, Pollonini G, Bambah-Mukku D, Blitzer RD, Alberini CM. 2011. A critical role for IGF-II in memory consolidation and enhancement. Nature 469: 491497. doi:10.1038/nature09667

Chin EWM, Lim WM, Ma D, Rosales FJ, Goh ELK. 2018. Choline rescues behavioural deficits in a mouse model of Rett syndrome by modulating neuronal plasticity. Mol Neurobiol 56: 3882-3896. doi:10.1007/ s12035-018-1345-9

Collins AL, Levenson JM, Vilaythong AP, Richman R, Armstrong DL, Noebels JL, David Sweatt J, Zoghbi HY. 2004. Mild overexpression of $\mathrm{MeCP} 2$ causes a progressive neurological disorder in mice. Hum Mol Genet 13: $2679-2689$. doi:10.1093/hmg/ddh282

Da Silva WC, Bonini JS, Bevilaqua LR, Medina JH, Izquierdo I, Cammarota M. 2008. Inhibition of mRNA synthesis in the hippocampus impairs consolidation and reconsolidation of spatial memory. Hippocampus 18: 29-39. doi:10.1002/hipo.20362

Davis HP, Squire LR. 1984. Protein synthesis and memory: a review. Psychol Bull 96: 518-559. doi:10.1037/0033-2909.96.3.518

Durand S, Patrizi A, Quast KB, Hachigian L, Pavlyuk R, Saxena A, Carninci P, Hensch TK, Fagiolini M. 2012. NMDA receptor regulation prevents regression of visual cortical function in the absence of Mecp2. Neuron 76: 1078-1090. doi:10.1016/j.neuron.2012.12.004

Figurov A, Pozzo-Miller LD, Olafsson P, Wang T, Lu B. 1996. Regulation of synaptic responses to high-frequency stimulation and LTP by neurotrophins in the hippocampus. Nature 381: 706-709. doi:10.1038/ 381706a0

Fyffe SL, Neul JL, Samaco RC, Chao HT, Ben-Shachar S, Moretti P, McGill BE, Goulding EH, Sullivan E, Tecott LH, et al. 2008. Deletion of Mecp2 in Sim1-expressing neurons reveals a critical role for MeCP2 in feeding behavior, aggression, and the response to stress. Neuron 59: 947-958. doi:10.1016/j.neuron.2008.07.030

Gabel HW, Kinde B, Stroud H, Gilbert CS, Harmin DA, Kastan NR, Hemberg M, Ebert DH, Greenberg ME. 2015. Disruption of DNA-methylation-dependent long gene repression in Rett syndrome. Nature 522: 89-93. doi:10.1038/nature14319

Garcia-Osta A, Tsokas P, Pollonini G, Landau EM, Blitzer R, Alberini CM. 2006. MuSK expressed in the brain mediates cholinergic responses, synaptic plasticity, and memory formation. J Neurosci 26: 7919-7932. doi:10.1523/JNEUROSCI.1674-06.2006

Gemelli T, Berton O, Nelson ED, Perrotti LI, Jaenisch R, Monteggia LM. 2006. Postnatal loss of methyl-CpG binding protein 2 in the forebrain is sufficient to mediate behavioral aspects of Rett syndrome in mice. Biol Psychiatry 59: 468-476. doi:10.1016/j.biopsych.2005.07.025

Guy J, Hendrich B, Holmes M, Martin JE, Bird A. 2001. A mouse Mecp2-null mutation causes neurological symptoms that mimic Rett syndrome. Nat Genet 27: 322-326. doi:10.1038/85899
Guy J, Gan J, Selfridge J, Cobb S, Bird A. 2007. Reversal of neurological defects in a mouse model of Rett syndrome. Science 315: 1143-1147. doi:10.1126/science.1138389

Guy J, Cheval H, Selfridge J, Bird A. 2011. The role of MeCP2 in the brain. Апnи Rev Cell Dev Biol 27: 631-652. doi:10.1146/ annurev-cellbio-092910-154121

Hao S, Tang B, Wu Z, Ure K, Sun Y, Tao H, Gao Y, Patel AJ, Curry DJ, Samaco RC, et al. 2015. Forniceal deep brain stimulation rescues hippocampal memory in Rett syndrome mice. Nature 526: 430-434. doi:10.1038/nature15694

Hebbes TR, Thorne AW, Crane-Robinson C. 1988. A direct link between core histone acetylation and transcriptionally active chromatin. EMBO J 7: 1395-1402. doi:10.1002/j.1460-2075.1988.tb02956.x

Hendrich B, Tweedie S. 2003. The methyl-CpG binding domain and the evolving role of DNA methylation in animals. Trends Genet 19: 269-277. doi:10.1016/S0168-9525(03)00080-5

Holliday R, Pugh JE. 1975. DNA modification mechanisms and gene activity during development. Science 187: 226-232. doi:10.1126/science .1111098

Igaz LM, Vianna MR, Medina JH, Izquierdo I. 2002. Two time periods of hippocampal mRNA synthesis are required for memory consolidation of fear-motivated learning. J Neurosci 22: 6781-6789. doi:10.1523/ JNEUROSCI.22-15-06781.2002

Ito-Ishida A, Ure K, Chen H, Swann JW, Zoghbi HY. 2015. Loss of MeCP2 in parvalbumin-and somatostatin-expressing neurons in mice leads to distinct Rett syndrome-like phenotypes. Neuron 88: 651-658. doi:10 $.1016 /$ j.neuron.2015.10.029

Kabra M, Robie AA, Rivera-Alba M, Branson S, Branson K. 2013. JAABA: interactive machine learning for automatic annotation of animal behavior. Nat Methods 10: 64-67. doi:10.1038/nmeth.2281

Kaludov NK, Wolffe AP. 2000. MeCP2 driven transcriptional repression in vitro: selectivity for methylated DNA, action at a distance and contacts with the basal transcription machinery. Nucleic Acids Res 28: 1921-1928. doi:10.1093/nar/28.9.1921

Kee SE, Mou X, Zoghbi HY, Ji D. 2018. Impaired spatial memory codes in a mouse model of Rett syndrome. eLife 7: e31451. doi:10.7554/eLife .31451

Kerr B, Alvarez-Saavedra M, Sáez MA, Saona A, Young JI. 2008. Defective body-weight regulation, motor control and abnormal social interactions in Mecp2 hypomorphic mice. Hum Mol Genet 17: 1707-1717. doi:10 $.1093 / \mathrm{hmg} / \mathrm{ddn} 061$

Kessels RP, de Haan EH, Kappelle LJ, Postma A. 2001. Varieties of human spatial memory: a meta-analysis on the effects of hippocampal lesions. Brain Res Brain Res Rev 35: 295-303. doi:10.1016/S0165-0173(01) 00058-3

Kokura K, Kaul SC, Wadhwa R, Nomura T, Khan MM, Shinagawa T, Yasukawa T, Colmenares C, Ishii S. 2001. The Ski protein family is required for MeCP2-mediated transcriptional repression. J Biol Chem 276: $34115-34121$. doi: $10.1074 /$ jbc.M105747200

Kriaucionis S, Bird A. 2003. DNA methylation and Rett syndrome. Hum Mol Genet 12: R221-R227. doi:10.1093/hmg/ddg286

Krishnan K, Lau BY, Ewall G, Huang ZJ, Shea SD. 2017. MECP2 regulates cortical plasticity underlying a learned behaviour in adult female mice. Nat Commun 8: 14077. doi:10.1038/ncomms14077

Lewis JD, Meehan RR, Henzel WJ, Maurer-Fogy I, Jeppesen P, Klein F, Bird A. 1992. Purification, sequence, and cellular localization of a novel chromosomal protein that binds to methylated DNA. Cell 69: 905-914. doi:10.1016/0092-8674(92)90610-O

Li W, Pozzo-Miller L. 2012. Beyond widespread Mecp2 deletions to model Rett syndrome: conditional spatio-temporal knockout, single-point mutations and transgenic rescue mice. Autism Open Access 2012: 5. doi:10.4172/2165-7890.S1-005

Li H, Zhong X, Chau KF, Williams EC, Chang Q. 2011. Loss of activity-induced phosphorylation of MeCP2 enhances synaptogenesis, LTP and spatial memory. Nat Neurosci 14: 1001-1008. doi:10.1038/nn .2866

Li W, Bellot-Saez A, Phillips ML, Yang T, Longo FM, Pozzo-Miller L. 2017. A small-molecule TrkB ligand restores hippocampal synaptic plasticity and object location memory in Rett syndrome mice. Dis Model Mech 10: 837-845. doi:10.1242/dmm.029959

Lioy DT, Garg SK, Monaghan CE, Raber J, Foust KD, Kaspar BK, Hirrlinger PG, Kirchhoff F, Bissonnette JM, Ballas N, et al. 2011. A role for glia in the progression of Rett's syndrome. Nature 475: 497-500. doi:10 .1038 /nature10214

Liu H, Chen Y, Niu Y, Zhang K, Kang Y, Ge W, Liu X, Zhao E, Wang C, Lin S, et al. 2014. TALEN-mediated gene mutagenesis in rhesus and cynomolgus monkeys. Cell Stem Cell 14: 323-328. doi:10.1016/j.stem .2014 .01 .018

Long SW, Ooi JY, Yau PM, Jones PL. 2011. A brain-derived MeCP2 complex supports a role for MeCP2 in RNA processing. Biosci Rep 31: 333-343. doi:10.1042/BSR20100124 
Lyst MJ, Ekiert R, Ebert DH, Merusi C, Nowak J, Selfridge J, Guy J, Kastan NR, Robinson ND, de Lima Alves F, et al. 2013. Rett syndrome mutations abolish the interaction of MeCP2 with the NCoR/SMRT co-repressor. Nat Neurosci 16: 898-902. doi:10.1038/nn.3434

Ma YL, Wang HL, Wu HC, Wei CL, Lee EH. 1998. Brain-derived neurotrophic factor antisense oligonucleotide impairs memory retention and inhibits long-term potentiation in rats. Neuroscience 82: 957-967. doi:10.1016/s0306-4522(97)00325-4

Ma DK, Guo JU, Ming GL, Song H. 2009. DNA excision repair proteins and Gadd45 as molecular players for active DNA demethylation. Cell Cycle 8: 1526-1531. doi:10.4161/cc.8.10.8500

Maunakea AK, Chepelev I, Cui K, Zhao K. 2013. Intragenic DNA methylation modulates alternative splicing by recruiting MeCP2 to promote exon recognition. Cell Res 23: 1256-1269. doi:10.1038/cr.2013.110

Maviel T, Durkin TP, Menzaghi F, Bontempi B. 2004. Sites of neocortical reorganization critical for remote spatial memory. Science 305: 96-99. doi:10.1126/science.1098180

McGraw CM, Samaco RC, Zoghbi HY. 2011. Adult neural function requires MeCP2. Science 333: 186. doi:10.1126/science.1206593

Meas R, Mao P. 2015. Histone ubiquitylation and its roles in transcription and DNA damage response. DNA Repair (Amst) 36: 36-42. doi:10.1016/j .dnarep.2015.09.016

Miller CA, Gavin CF, White JA, Parrish RR, Honasoge A, Yancey CR, Rivera IM, Rubio MD, Rumbaugh G, Sweatt JD. 2010. Cortical DNA methylation maintains remote memory. Nat Neurosci 13: 664-666. doi: $10.1038 / \mathrm{nn} .2560$

Moretti P, Bouwknecht JA, Teague R, Paylor R, Zoghbi HY. 2005. Abnormalities of social interactions and home-cage behavior in a mouse model of Rett syndrome. Hum Mol Genet 14: 205-220. doi:10.1093/ $\mathrm{hmg} / \mathrm{ddi} 016$

Moretti P, Levenson JM, Battaglia F, Atkinson R, Teague R, Antalffy B, Armstrong D, Arancio O, Sweatt JD, Zoghbi HY. 2006. Learning and memory and synaptic plasticity are impaired in a mouse model of Rett syndrome. J Neurosci 26: $319-327$. doi:10.1523/JNEUROSCI.2623-05 .2006

Moy SS, Nadler JJ, Perez A, Barbaro RP, Johns JM, Magnuson TR, Piven J, Crawley JN. 2004. Sociability and preference for social novelty in five inbred strains: an approach to assess autistic-like behavior in mice. Genes Brain Behav 3: 287-302. doi:10.1111/j.1601-1848.2004.00076.x

Mujtaba S, Zeng L, Zhou MM. 2007. Structure and acetyl-lysine recognition of the bromodomain. Oncogene 26: 5521-5527. doi:10.1038/sj.onc .1210618

Na ES, Nelson ED, Adachi M, Autry AE, Mahgoub MA, Kavalali ET, Monteggia LM. 2012. A mouse model for MeCP2 duplication syndrome: MeCP2 overexpression impairs learning and memory and synaptic transmission. J Neurosci 32: 3109-3117. doi:10.1523/JNEUROSCI $.6000-11.2012$

Nan X, Tate P, Li E, Bird A. 1996. DNA methylation specifies chromosomal localization of MeCP2. Mol Cell Biol 16: 414-421. doi:10.1128/MCB.16 .1 .414

Nan X, Campoy FJ, Bird A. 1997. MeCP2 is a transcriptional repressor with abundant binding sites in genomic chromatin. Cell 88: 471-481. doi:10 1016/S0092-8674(00)81887-5

Nan X, Ng HH, Johnson CA, Laherty CD, Turner BM, Eisenman RN, Bird A. 1998. Transcriptional repression by the methyl-CpG-binding protein MeCP2 involves a histone deacetylase complex. Nature 393: 386-389. doi: $10.1038 / 30764$

Neul JL, Fang P, Barrish J, Lane J, Caeg EB, Smith EO, Zoghbi H, Percy A, Glaze DG. 2008. Specific mutations in methyl-CpG-binding protein 2 confer different severity in Rett syndrome. Neurology 70: 1313-1321. doi:10.1212/01.wnl.0000291011.54508.aa

Niu Y, Shen B, Cui Y, Chen Y, Wang J, Wang L, Kang Y, Zhao X, Si W, Li W, et al. 2014. Generation of gene-modified cynomolgus monkey via Cas9/ RNA-mediated gene targeting in one-cell embryos. Cell 156: 836-843. doi:10.1016/j.cell.2014.01.027

Ohayon S, Avni O, Taylor AL, Perona P, Roian Egnor SE. 2013. Automated multi-day tracking of marked mice for the analysis of social behaviour. $J$ Neurosci Methods 219: 10-19. doi:10.1016/j.jneumeth.2013.05.013

Olton DS, Walker JA, Gage FH. 1978. Hippocampal connections and spatial discrimination. Brain Res 139: 295-308. doi:10.1016/0006-8993(78) 90930-7

Paul CM, Magda G, Abel S. 2009. Spatial memory: theoretical basis and comparative review on experimental methods in rodents. Behav Brain Res 203: 151-164. doi:10.1016/j.bbr.2009.05.022

Pearson BL, Defensor EB, Pobbe RL, Yamamoto LH, Bolivar VJ, Blanchard DC, Blanchard RJ. 2012. Mecp2 truncation in male mice promotes affiliative social behavior. Behav Genet 42: 299-312. doi:10 $.1007 / \mathrm{s} 10519-011-9501-2$

Pedreira ME, Dimant B, Maldonado H. 1996. Inhibitors of protein and RNA synthesis block context memory and long-term habituation in the crab Chasmagnathus. Pharmacol Biochem Behav 54: 611-617. doi:10.1016/ 0091-3057(95)02206-6
Phillips RG, LeDoux JE. 1992. Differential contribution of amygdala and hippocampus to cued and contextual fear conditioning. Behav Neurosci 106: $274-285$. doi: $10.1037 / 0735-7044.106 .2 .274$

Phillips ML, Robinson HA, Pozzo-Miller L. 2019. Ventral hippocampal projections to the medial prefrontal cortex regulate social memory. eLife 8: e44182. doi:10.7554/eLife.44182

Pitcher MR, Herrera JA, Buffington SA, Kochukov MY, Merritt JK, Fisher AR, Schanen NC, Costa-Mattioli M, Neul JL. 2015. Rett syndrome like phenotypes in the R255X Mecp2 mutant mouse are rescued by MECP2 transgene. Hum Mol Genet 24: 2662-2672. doi:10.1093/hmg/ddv030

Rakyan VK, Preis J, Morgan HD, Whitelaw E. 2001. The marks, mechanisms and memory of epigenetic states in mammals. Biochem J 356: 1-10. doi:10.1042/bj3560001

Raman AT, Pohodich AE, Wan YW, Yalamanchili HK, Lowry WE, Zoghbi HY, Liu Z. 2018. Apparent bias toward long gene misregulation in MeCP2 syndromes disappears after controlling for baseline variations. Nat Commun 9: 3225. doi:10.1038/s41467-018-05627-1

Ramocki MB, Tavyev YJ, Peters SU. 2010. The MECP2 duplication syndrome. Am J Med Genet A 152A: 1079-1088. doi:10.1002/ajmg.a.33184

Robertson KD, Wolffe AP. 2000. DNA methylation in health and disease. Nat Rev Genet 1: 11-19. doi:10.1038/35049533

Robie AA, Seagraves KM, Egnor SE, Branson K. 2017. Machine vision methods for analyzing social interactions. J Exp Biol 220: 25-34. doi:10 $.1242 /$ jeb. 142281

Samaco RC, Fryer JD, Ren J, Fyffe S, Chao HT, Sun Y, Greer JJ, Zoghbi HY, Neul JL. 2008. A partial loss of function allele of methyl-CpG-binding protein 2 predicts a human neurodevelopmental syndrome. Hum Mol Genet 17: 1718-1727. doi:10.1093/hmg/ddn062

Samaco RC, Mandel-Brehm C, Chao HT, Ward CS, Fyffe-Maricich SL, Ren J, Hyland K, Thaller C, Maricich SM, Humphreys P, et al. 2009. Loss of MeCP2 in aminergic neurons causes cell-autonomous defects in neurotransmitter synthesis and specific behavioral abnormalities. Proc Natl Acad Sci 106: 21966-21971. doi:10.1073/pnas.0912257106

Samaco RC, McGraw CM, Ward CS, Sun Y, Neul JL, Zoghbi HY. 2013. Female $\mathrm{Mecp}^{+/-}$mice display robust behavioral deficits on two different genetic backgrounds providing a framework for pre-clinical studies. Hum Mol Genet 22: 96-109. doi: $10.1093 / \mathrm{hmg} / \mathrm{dds} 406$

Sánchez-Álvarez M, Montes M, Sánchez-Hernández N, Hernández-Munain C, Suñé C. 2010. Differential effects of sumoylation on transcription and alternative splicing by transcription elongation regulator 1 (TCERG1). J Biol Chem 285: 15220-15233. doi:10.1074/jbc .M109.063750

Schaevitz LR, Moriuchi JM, Nag N, Mellot TJ, Berger-Sweeney J. 2010. Cognitive and social functions and growth factors in a mouse model of Rett syndrome. Physiol Behav 100: 255-263. doi:10.1016/j.physbeh .2009 .12 .025

Shahbazian M, Young J, Yuva-Paylor L, Spencer C, Antalffy B, Noebels J, Armstrong D, Paylor R, Zoghbi H. 2002. Mice with truncated MeCP2 recapitulate many Rett syndrome features and display hyperacetylation of histone H3. Neuron 35: 243-254. doi:10.1016/S0896-6273(02) 00768-7

Silverman JL, Yang M, Lord C, Crawley JN. 2010. Behavioural phenotyping assays for mouse models of autism. Nat Rev Neurosci 11: 490-502. doi:10 $.1038 / \mathrm{nrn} 2851$

Stearns NA, Schaevitz LR, Bowling H, Nag N, Berger UV, Berger-Sweeney J. 2007. Behavioral and anatomical abnormalities in Mecp2 mutant mice: a model for Rett syndrome. Neuroscience 146: 907-921. doi:10.1016/j .neuroscience.2007.02.009

Tao J, Hu K, Chang Q, Wu H, Sherman NE, Martinowich K, Klose RJ, Schanen C, Jaenisch R, Wang W, et al. 2009. Phosphorylation of MeCP2 at Serine 80 regulates its chromatin association and neurological function. Proc Natl Acad Sci 106: 4882-4887. doi:10.1073/pnas .0811648106

Taubenfeld SM, Milekic MH, Monti B, Alberini CM. 2001. The consolidation of new but not reactivated memory requires hippocampal C/EBPbeta. Nat Neurosci 4: 813-818. doi:10.1038/90520

Thut PD, Lindell TJ. 1974. $\alpha$-amanitin inhibition of mouse brain form II ribonucleic acid polymerase and passive avoidance retention. $\mathrm{Mol}$ Pharmacol 10: 146-154.

Tully T, Preat T, Boynton SC, Del Vecchio M. 1994. Genetic dissection of consolidated memory in Drosophila. Cell 79: 35-47. doi:10.1016/ 0092-8674(94)90398-0

Van Esch H, Bauters M, Ignatius J, Jansen M, Raynaud M, Hollanders K, Lugtenberg D, Bienvenu T, Jensen LR, Gécz J, et al. 2005. Duplication of the MECP2 region is a frequent cause of severe mental retardation and progressive neurological symptoms in males. Am J Hum Genet 77: 442453. doi:10.1086/444549

Veeraragavan S, Wan YW, Connolly DR, Hamilton SM, Ward CS, Soriano S, Pitcher MR, McGraw CM, Huang SG, Green JR, et al. 2016. Loss of $\mathrm{MeCP} 2$ in the rat models regression, impaired sociability and transcriptional deficits of Rett syndrome. Hum Mol Genet 25: 3284-3302. doi:10.1093/hmg/ddw178 
Wetzel W, Ott T, Matthies H. 1976. Is actinomycin D suitable for the investigation of memory processes? Pharmacol Biochem Behav 4: 515519. doi:10.1016/0091-3057(76)90190-8

Whetstine JR. 2009. Histone methylation: chemically inert by chromatin dynamic. In Handbook of cell signaling, 2nd ed. (ed. RA Bradshaw, EA Dennis), pp. 2389-2397. Academic, Burlington, MA.

Wolffe AP, Jones PL, Wade PA. 1999. DNA demethylation. Proc Natl Acad Sci 96: 5894-5896. doi:10.1073/pnas.96.11.5894

Wu Y, Zhong W, Cui N, Johnson CM, Xing H, Zhang S, Jiang C. 2016. Characterization of Rett Syndrome-like phenotypes in Mecp2-knockout rats. I Neurodev Disord 8: 23, doi:10.1186/s11689-016-9156-7

Yasui DH, Peddada S, Bieda MC, Vallero RO, Hogart A, Nagarajan RP, Thatcher KN, Farnham PJ, Lasalle JM. 2007. Integrated epigenomic analyses of neuronal MeCP2 reveal a role for long-range interaction with active genes. Proc Natl Acad Sci 104: 19416-19421. doi:10.1073/pnas .0707442104
Zhang Y. 2003. Transcriptional regulation by histone ubiquitination and deubiquitination. Genes Dev 17: 2733-2740. doi:10.1101/gad .1156403

Zhou Z, Hong EJ, Cohen S, Zhao WN, Ho HY, Schmidt L, Chen WG, Lin Y, Savner E, Griffith EC, et al. 2006. Brain-specific phosphorylation of MeCP2 regulates activity-dependent Bdnf transcription, dendritic growth, and spine maturation. Neuron 52: 255-269. doi:10.1016/j .neuron.2006.09.037

Zovkic IB, Guzman-Karlsson MC, Sweatt JD. 2013. Epigenetic regulation of memory formation and maintenance. Learn Mem 20: 61-74. doi:10 $.1101 / \mathrm{lm} .026575 .112$

Received April 2, 2019; accepted in revised form May 21, 2019. 


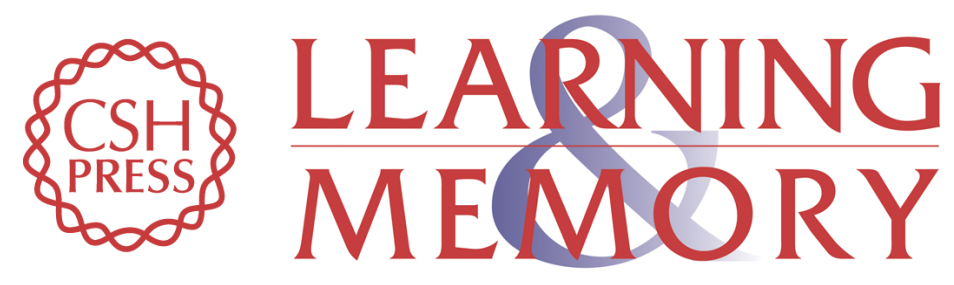

\section{The role of MeCP2 in learning and memory}

Holly A. Robinson and Lucas Pozzo-Miller

Learn. Mem. 2019, 26:

Access the most recent version at doi:10.1101//m.048876.118

References This article cites 100 articles, 25 of which can be accessed free at: http://learnmem.cshlp.org/content/26/9/343.full.html\#ref-list-1

Creative This article is distributed exclusively by Cold Spring Harbor Laboratory Press for the Commons first 12 months after the full-issue publication date (see

License http://learnmem.cshlp.org/site/misc/terms.xhtml). After 12 months, it is available under a Creative Commons License (Attribution-NonCommercial 4.0 International), as described at http://creativecommons.org/licenses/by-nc/4.0/.

Email Alerting Receive free email alerts when new articles cite this article - sign up in the box at the Service top right corner of the article or click here. 